\title{
Novel HPLC method for Levofloxacin and Its known impurities in Tablets dosage form
}

Authors \& Affiliation:

Ganpisetti Srinivasa Rao ${ }^{1,2 *}$,

K. Basavaiah ${ }^{2}$, P. Sunil Reddy ${ }^{1}$,

L. Kalyanaraman ${ }^{1}$, B. M. Rao ${ }^{1} \&$

S. Raj Kumar ${ }^{3}$

1. IPDO, Dr. Reddys, Laboratories, Bachupally,

Hyderabad, Telangana, India

2. Dept. of Chemistry, Andhra University,

Visakhapatnam, Andhra Pradesh, India

3.Lotus Pharmaceutical Co. Ltd, No-30,

Chenggong $1^{\text {st }} \mathrm{Rd}$, Sinsing Village, Nantou

City, Nantou County 540, Taiwan.

\section{Corresponding Author}

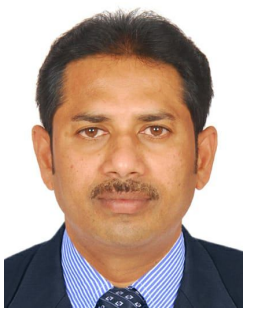

Ganpisetti Srinivasa Rao

(C) 2020.The Authors. Published under

Caribbean Journal of Science and

Technology

ISSN 0799-3757

http://caribjscitech.com/

\begin{abstract}
:
Levofloxacin is a fluoroquinolone antibiotic that fights bacteria in the body. Levofloxacin is used to treat different types of bacterial infections. Simple HPLC method for Levofloxacin and six known impurities was developed and validated. Buffer: $8.5 \mathrm{~g}$ ammonium acetate, $1.25 \mathrm{~g}$ cupric sulphate and 1.g L-Isoleucine in $1000 \mathrm{ml}$ water. Mobile phase: Buffer and methanol 70:30 v/v; Diluent: Mobile phase; Column: Inertsil ODS-3V C18, $250 * 4.6 \mathrm{~mm}, 5 \mu$; Injection volume: $25 \mu \mathrm{L}$; Column temperature $42^{\circ} \mathrm{C}$; Flow rate: $0.7 \mathrm{ml} / \mathrm{min}$; Run time: $60 \mathrm{~min}$; Detector: $340 \mathrm{~nm}$. System suitability limits are NMT 10\% RSD for 5 replicates and tailing factor NMT 1.8. Method validation was performed with precision, specificity, accuracy, linearity, limit of detection and quantification, ruggedness and robustness. Finalized method produced linear response in the specification limit was 0.998 to 1.000 correlation coefficient for levofloxacin and percentage recovery was found to be $98.00 \%$ to $102.0 \%$.
\end{abstract}

Keywords: Levofloxacin, known impurities, HPLC method, United States of Pharmacopoeia. 


\section{Introduction:}

Levofloxacin is a bacteriostatic L-isomer of ofloxacin and it is a third generation fluoroquinolone medicine. Chemically, levofloxacin is (-)-(S)-9-fluoro-2, 3-dihydro-3-methyl-10-(4-methyl-1piperazinyl)-7-oxo7H-pyrido[1,2,3-de]-1,4-benzoxazine-6-carboxylic acid hemihydrate[1]. Levofloxacin is used to treat severe or life-threatening bacterial infections or bacterial infections that have failed to respond to other antibiotic classes[2-3]. Levofloxacin inhibits bacterial type II topoisomerases, topoisomerase IV and DNA gyrase[4-7]. Levofloxacin, like other fluoroquinolones, inhibits the A subunits of DNA gyrase, two subunits encoded by the gyrA gene. levofloxacin and its impurities chemical structures were represented in figure- 1 .

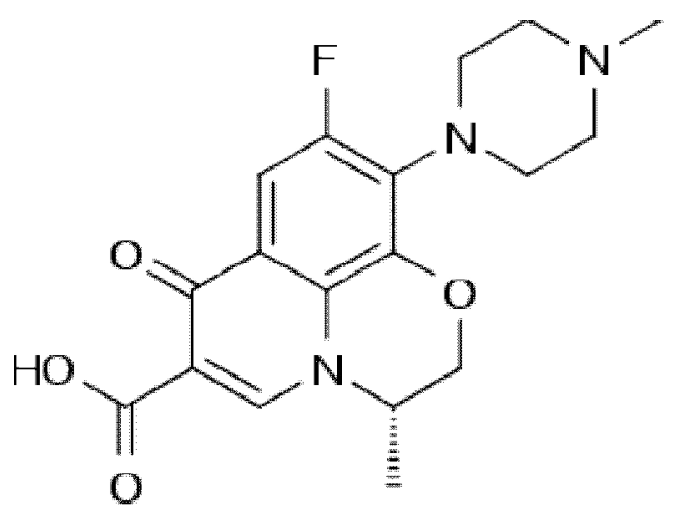

Figure-1: Levofloxacin and its impurities chemical structures

Literature confirmed the few reported methods to determine the levofloxacin and its combination with other drug products[8-14]. Goswami (2018), Sivasubramanian (2018) were reported combination method, Eldin (2018) reported levofloxacin and Daclastavir method. Objective of this method was to develop a simple and accurate method for six known impurities and Levofloxacin in tablets dosage form. USP method listed for four impurities but other two impurities are forming during product manufacturing and storage conditions.

\section{Materials and Method:}

\section{Chemicals \& Instrument:}

Ammonium acetate, Cupric sulphate and L-Isoleucine AR grades; acetonitrile and methanol (HPLC grade); Water (Milli-Q grade); Waters alliance HPLC instrument with PDA detector; Inertsil ODS$3 \mathrm{~V} \mathrm{C} 18,250 * 4.6 \mathrm{~mm}, 5 \mu$.

\section{Solutions preparation:}

Buffer: $8.5 \mathrm{~g}$ ammonium acetate, $1.25 \mathrm{~g}$ cupric sulphate and 1.g L-Isoleucine in $1000 \mathrm{ml}$ water. Mobile phase: Buffer and methanol 70:30 v/v

Diluent: Mobile phase

Std. soln.: $20 \mathrm{mg}$ Levofloxacin std. in 100ml volumetric flask and dilution with diluent. $5 \mathrm{ml}$ of above solution dilute with $50 \mathrm{ml}$ diluent. $5 \mathrm{ml}$ of solution dilute $25 \mathrm{ml}$ with diluent. 
Impurity stock: All known impurities each $2 \mathrm{mg}$, D-isomer $5 \mathrm{mg}$ in $10 \mathrm{ml}$ and dilution with diluent. $2 \mathrm{ml}$ of solution dilute with $50 \mathrm{ml}$ diluent.

Identification sol.: $10 \mathrm{mg}$ Levofloxacin std. and $4 \mathrm{ml}$ of impurity stock solution in to $50 \mathrm{ml}$ and dilute with diluent.

Test sol.: $20 \mathrm{mg}$ levofloxacin equivalent tablets fine powder in to $100 \mathrm{ml}$ and dilute with diluent. Sonicate 30min with intermediate shaking and filter with $0.45 \mu$ NYLON filter.

\section{Chromatographic conditions:}

Column: Inertsil ODS-3V C18, 250*4.6mm, $5 \mu$; Injection volume: $25 \mu \mathrm{L}$; Column temperature $42^{\circ} \mathrm{C}$; Flow rate: $0.7 \mathrm{ml} / \mathrm{min}$; Run time: $60 \mathrm{~min}$; Detector: $340 \mathrm{~nm}$.

System suitability limits: NMT 10\% RSD for 5 replicates and tailing factor NMT 1.8 .

\section{Results and Discussion:}

\section{Method optimization:}

Method development was performed to separate all known impurities and Levofloxacin. Levofloxacin has official monograph in United States of Pharmacopoeia (USP), impurities method is by HPLC. USP Impurities method was specified four known impurities with acceptable limits. However, the main objective of this research was to develop a simple HPLC method for six known impurities. Initial method development was started as per the USP monograph.

\section{Monograph method:}

Mobile phase: $874 \mathrm{~g}$ Cupric sulphate $918 \mathrm{~g} \mathrm{~L}$-isoleucine and $5.94 \mathrm{~g}$ ammonium acetate in to $700 \mathrm{ml}$ water and 300ml methanol; Diluent: Acetonitrile and water 20:80 v/v; Column: L1 packing 250*4.6mm, $5 \mu$; Injection volume: $25 \mu \mathrm{L}$; Column temperature: $45^{\circ} \mathrm{C}$; Flow rate: $0.8 \mathrm{ml} / \mathrm{min}$; Runtime: 2 times of levofloxacin RT; Wavelength: 360nm; System suitability: \%RSD for Levofloxacin peak is NMT 2.0\%; Tailing factor for standard peak NMT 1.8 .

USP monograph impurities and objective method impurities were listed in below table-1.

Table-1: USP and objective method impurity profile comparison

\begin{tabular}{|c|c|c|c|c|}
\hline $\begin{array}{c}\text { S. } \\
\text { No. }\end{array}$ & Impurity name & $\begin{array}{c}\text { USP } \\
\text { (NMT) }\end{array}$ & $\begin{array}{c}\text { Objective method } \\
\text { limit (NMT) }\end{array}$ & Remarks \\
\hline 1 & 10-fluoro levofloxacin & NA & $0.1 \%$ & Objective impurity \\
\hline 2 & Decarboxy levofloxacin & $0.3 \%$ & ----- & $\begin{array}{c}\text { Controlled and } \\
\text { listed as } \\
\text { unspecified. }\end{array}$ \\
\hline 3 & $\begin{array}{c}\text { Levofloxacin impurity A } \\
\text { (piperzine analog) }\end{array}$ & $0.7 \%$ & $0.2 \%$ & $\begin{array}{c}\text { Stringent limit than } \\
\text { USP. }\end{array}$ \\
\hline 4 & $\begin{array}{c}\text { Diamine derivative } \\
\end{array}$ & $0.3 \%$ & ---- & $\begin{array}{c}\text { Controlled and } \\
\text { listed as } \\
\text { unspecified. }\end{array}$ \\
\hline
\end{tabular}




\begin{tabular}{|c|c|c|c|c|}
\hline 5 & N-oxide impurity & $0.7 \%$ & $0.40 \%$ & $\begin{array}{c}\text { Stringent limit than } \\
\text { USP. }\end{array}$ \\
\hline 6 & 9-desfluoro levofloxacin & \multirow{3}{*}{$\begin{array}{l}\text { Other } \\
\text { method }\end{array}$} & ---- & \multirow{3}{*}{$\begin{array}{c}\text { Controlled and } \\
\text { listed as } \\
\text { unspecified. }\end{array}$} \\
\hline 7 & $\begin{array}{l}\text { Dextrofloxacin / D- } \\
\text { isomer }\end{array}$ & & ---- & \\
\hline 8 & 9-piperazino isomer & & ---- & \\
\hline 9 & Ethyl ester impurity & NA & $0.2 \%$ & Objective impurity \\
\hline
\end{tabular}

Method development was progressed to separate all the six impurities with different mobile phase conditions and columns. Finalized method was compared with USP monograph method and equivalency was performed. USP monograph method chromatogram was represented in below figure-2.

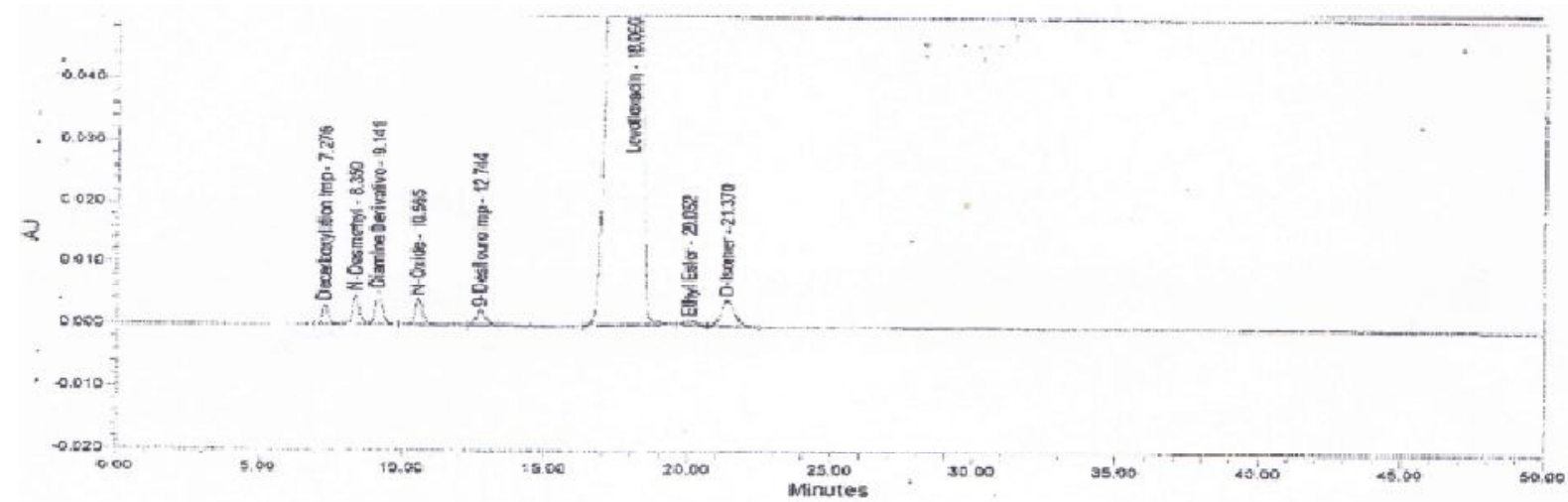

Figure-2: USP monograph method chromatogram

\section{USP method observations:}

Ethyl ester impurity was eluting nearest Levofloxacin peak (RRT 1.1) resolution was poor and recovery was found below 85\%. 10-Fluoro Levofloxacin impurity peak eluted at same RRT of Disomer impurity.

Developed method was separated Ethyl ester impurity and 10-fluoro levofloxacin impurity. Mobile phase was modified with phosphate buffer and column was changed and used Discovery HS F5, $150 * 4.6 \mathrm{~mm}, 5 \mu$ column. Optimized method was validated as per the industry guidance and general practice.

\section{Method validation:}

\section{System suitability:}

Chromatographic conditions were applied to confirm the system suitability limits \%RSD and tailing factor. \%RSD was found $1.28 \%$ and tailing factor 1.1. Each impurities identification solution and spiked solutions were injected and confirmed the RRT values for each known impurity. RRF values were established with two different concentration levels. All impurities specification limits, RT, 
RRT and RRF values were listed in below table-2. Diluted standard solution chromatogram was represented in figure-3. System suitability results were listed in table-3.

Table-2: Impurities RT, RRT and RRF values with specification limits.

\begin{tabular}{|c|c|c|c|c|c|}
\hline $\begin{array}{c}\text { S. } \\
\text { No. }\end{array}$ & Impurity name & RT (min) & RRT & Limit (\%) & RRF \\
\hline 1 & Levofloxacin & 23.06 & NA & NA & 1.0 \\
\hline 2 & Decarboxylation impurity & 9.13 & 0.40 & 0.1 & 1.1 \\
\hline 3 & N-Desmethyl levofloxacin & 11.26 & 0.49 & 0.2 & 1.03 \\
\hline 4 & Diamine derivative & 12.53 & 0.54 & 0.1 & 0.77 \\
\hline 5 & N-Oxide impurity & 14.31 & 0.62 & 0.3 & 0.9 \\
\hline 6 & 9-desfluro impurity & 16.80 & 0.73 & 0.3 & 0.62 \\
\hline 7 & Ethyl ester impurity & 26.27 & 1.14 & 0.2 & 0.73 \\
\hline 8 & D-isomer impurity & 28.89 & 1.25 & 0.8 & 0.97 \\
\hline
\end{tabular}

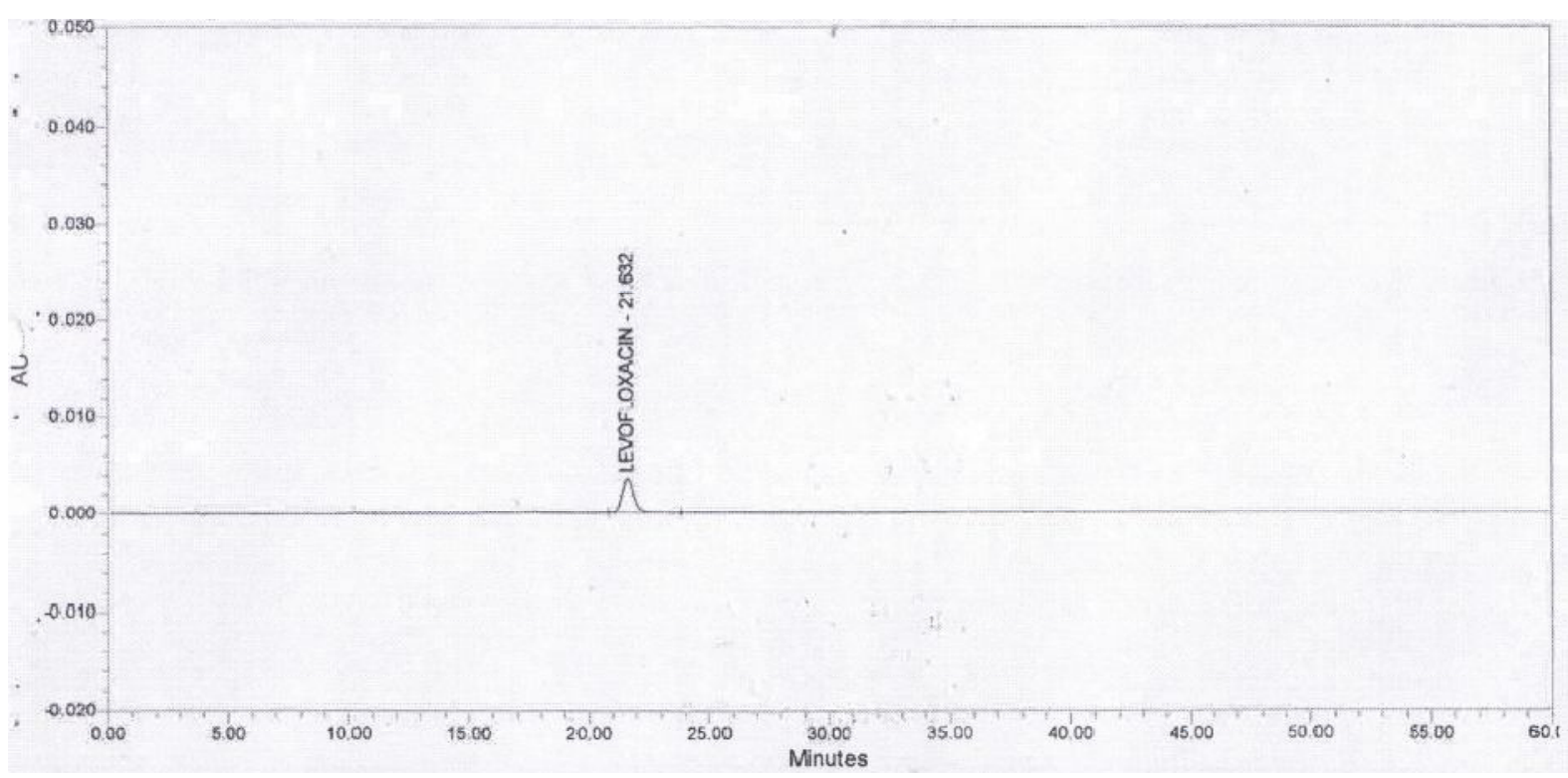

Figure-3: Diluted standard chromatogram

Table-3: Standard solution system suitability results

\begin{tabular}{|c|c|c|c|c|c|c|c|c|c|}
\hline $\begin{array}{c}\text { Sys. } \\
\text { Suit. }\end{array}$ & $\mathbf{1}$ & $\mathbf{2}$ & $\mathbf{3}$ & $\mathbf{4}$ & $\mathbf{5}$ & $\mathbf{6}$ & Avg. & $\begin{array}{c}\text { \%RS } \\
\text { D }\end{array}$ & Limit \\
\hline Area & 120808 & 120870 & 119963 & 119867 & 123979 & 122103 & 121265 & 1.28 & $10 \%$ \\
\hline Tailing & 1.1 & 1.2 & 1.1 & 1.2 & 1.2 & 1.1 & 1.15 & NA & 1.8 \\
\hline
\end{tabular}




\section{Precision:}

Method precision and system precision was performed for levofloxacin $750 \mathrm{mg}$ tablets as per the test procedure mentioned in materials and method. Six preparations were performed and intermediate precision was performed on different HPLC with different column and analyst. Precision results were tabulated for all spiked known impurities and \%RSD was calculated. Precision and intermediate precision results were tabulated in table-4. As such test sample and known impurities spiked sample chromatograms were represented in figure-4 and 5.

Table-4: Precision and intermediate precision results

\begin{tabular}{|c|c|c|c|c|c|c|c|c|}
\hline \multirow[t]{2}{*}{ Impurity name } & \multicolumn{6}{|c|}{ Precision samples } & \multirow[t]{2}{*}{ Avg. } & \multirow{2}{*}{$\begin{array}{c}\% \mathrm{RS} \\
\mathrm{D}\end{array}$} \\
\hline & 1 & 2 & 3 & 4 & 5 & 6 & & \\
\hline $\begin{array}{c}\text { Decarboxylation } \\
\text { impurity }\end{array}$ & 0.099 & 0.106 & 0.101 & 0.104 & 0.101 & 0.102 & 0.102 & 2.43 \\
\hline $\begin{array}{l}\text { N-Desmethyl } \\
\text { levofloxacin }\end{array}$ & 0.212 & 0.222 & 0.216 & 0.220 & 0.209 & 0.216 & 0.216 & 2.24 \\
\hline Diamine derivative & 0.115 & 0.119 & 0.110 & 0.116 & 0.108 & 0.112 & 0.113 & 3.60 \\
\hline N-Oxide impurity & 0.313 & 0.331 & 0.320 & 0.325 & 0.317 & 0.320 & 0.321 & 1.96 \\
\hline 9-desfluro impurity & 0.328 & 0.346 & 0.335 & 0.345 & 0.332 & 0.337 & 0.337 & 2.12 \\
\hline Ethyl ester impurity & 0.187 & 0.201 & 0.188 & 0.195 & 0.190 & 0.189 & 0.192 & 2.79 \\
\hline D-isomer impurity & 0.783 & 0.844 & 0.807 & 0.829 & 0.787 & 0.809 & 0.810 & 2.91 \\
\hline Total impurities & 2.33 & 2.47 & 2.37 & 2.43 & 2.34 & 2.38 & 2.89 & 2.16 \\
\hline \multirow[t]{2}{*}{ Impurity name } & \multicolumn{6}{|c|}{ Intermediate Precision samples } & \multirow[t]{2}{*}{ Avg. } & \multirow{2}{*}{$\begin{array}{c}\% \mathrm{RS} \\
\mathrm{D}\end{array}$} \\
\hline & 1 & 2 & 3 & 4 & 5 & 6 & & \\
\hline $\begin{array}{l}\text { Decarboxylation } \\
\text { impurity }\end{array}$ & 0.111 & 0.113 & 0.111 & 0.111 & 0.112 & 0.11 & 0.112 & 0.88 \\
\hline $\begin{array}{l}\text { N-Desmethyl } \\
\text { levofloxacin }\end{array}$ & 0.231 & 0.227 & 0.226 & 0.226 & 0.224 & 0.224 & 0.226 & 1.14 \\
\hline Diamine derivative & 0.118 & 0.116 & 0.118 & 0.118 & 0.118 & 0.118 & 0.118 & 0.69 \\
\hline N-Oxide impurity & 0.323 & 0.322 & 0.321 & 0.337 & 0.319 & 0.323 & 0.324 & 1.99 \\
\hline 9-desfluro impurity & 0.324 & 0.303 & 0.304 & 0.320 & 0.314 & 0.323 & 0.315 & 2.97 \\
\hline Ethyl ester impurity & 0.177 & 0.176 & 0.182 & 0.179 & 0.178 & 0.177 & 0.178 & 1.20 \\
\hline D-isomer impurity & 0.820 & 0.821 & 0.813 & 0.821 & 0.820 & 0.822 & 0.820 & 0.40 \\
\hline Total impurities & 2.387 & 2.361 & 2.358 & 2.395 & 2.368 & 2.383 & 2.375 & 0.64 \\
\hline
\end{tabular}




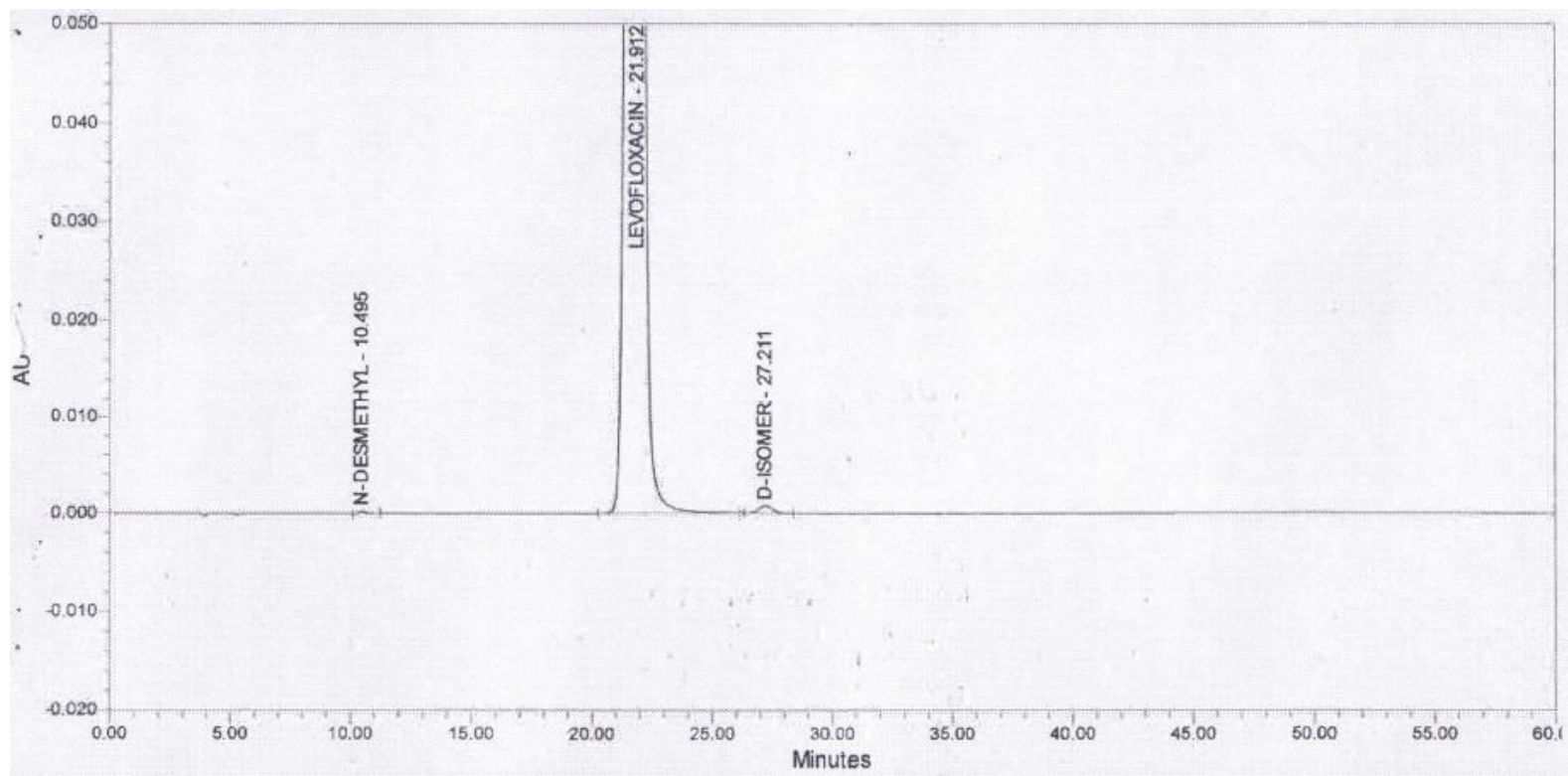

Figure-4: As such sample chromatogram

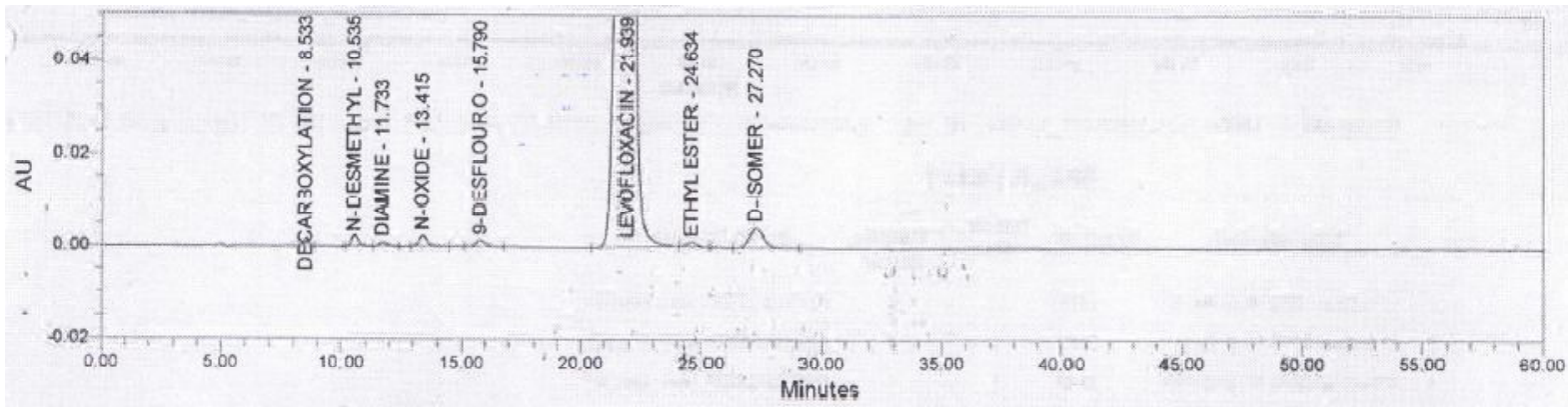

Figure-5: Impurities spiked sample chromatogram

\section{Specificity:}

Specificity was performed to evaluate the degradation behaviour of the formulation drug product. Acidic, basic, peroxide, thermal UV light, water and humidity stress conditions were applied. Peak purity plot and \% degradation were calculated and reported in table-5. Degradation studies chromatogram peak purity plots were represented in figure-6 to 13. 
Table-5: Degradation conditions and results.

\begin{tabular}{|c|c|c|c|c|c|c|}
\hline S. & \multirow[t]{2}{*}{ Stress condition } & \multirow{2}{*}{$\begin{array}{c}\% \text { Net } \\
\text { degradation }\end{array}$} & \multicolumn{3}{|c|}{ Peak purity } & \multirow{2}{*}{$\begin{array}{c}\text { Mass } \\
\text { balance }\end{array}$} \\
\hline No. & & & Angle & Threshold & Flag & \\
\hline 1 & As such & 0.284 & 0.121 & 0.290 & $\mathrm{NO}$ & NA \\
\hline 2 & Acid $\left(5 \mathrm{~N} \mathrm{HCl} / 24 \mathrm{hr} 70^{\circ} \mathrm{C}\right)$ & 0.27 & 0.694 & 1.242 & NO & 103.74 \\
\hline 3 & Base $\left(5 \mathrm{~N} \mathrm{NaOH} / 24 \mathrm{hr} 70^{\circ} \mathrm{C}\right)$ & 0.322 & 0.657 & 1.257 & $\mathrm{NO}$ & 104.21 \\
\hline 4 & Peroxide $\% \mathrm{H}_{2} \mathrm{O}_{2}$ & 4.235 & 0.799 & 1.674 & $\mathrm{NO}$ & 95.47 \\
\hline 5 & Thermal $105^{\circ} \mathrm{C} / 7$ days & 0.581 & 0.096 & 0.296 & $\mathrm{NO}$ & 103.36 \\
\hline 6 & Water $24 \mathrm{hr} / 70^{\circ} \mathrm{C}$ & 0.322 & 0.279 & 0.523 & $\mathrm{NO}$ & 102.60 \\
\hline 7 & $\begin{array}{c}\text { Humidity } 90 \% \text { RH } 25^{\circ} \mathrm{C} / \\
\text { 7days }\end{array}$ & 0.368 & 0.525 & 1.109 & $\mathrm{NO}$ & 96.50 \\
\hline 8 & $\begin{array}{l}\text { UV/ Sunlight } 200 \mathrm{w} \mathrm{hr} / \mathrm{sq} / \\
1.2 \mathrm{mil} \mathrm{lux} \mathrm{hr}\end{array}$ & 0.279 & 0.149 & 0.288 & $\mathrm{NO}$ & 104.67 \\
\hline
\end{tabular}

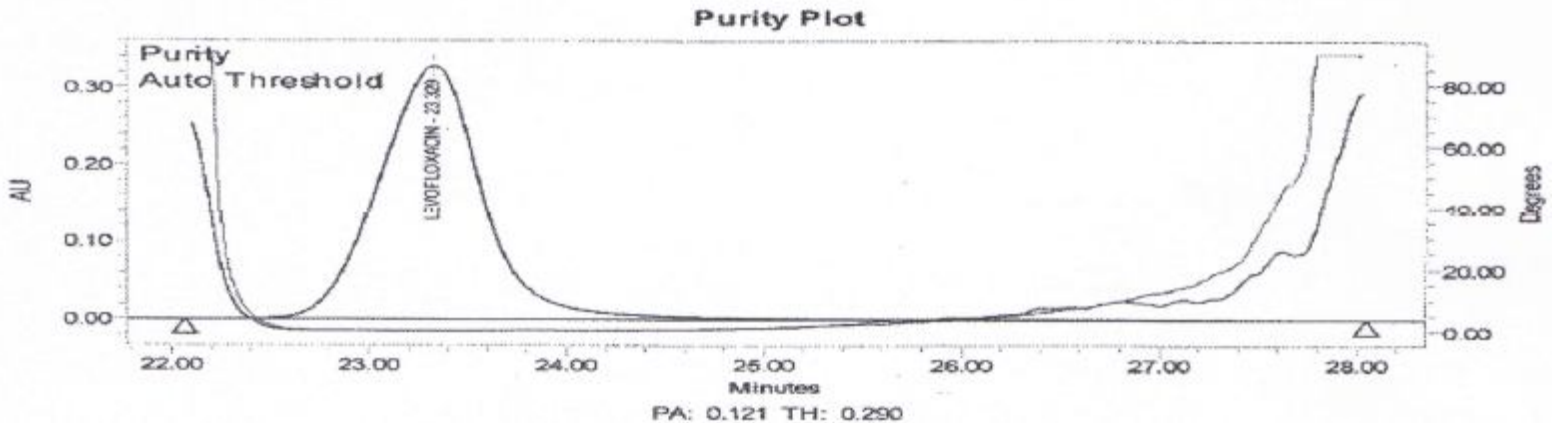

Figure-6: As such sample peak purity plot

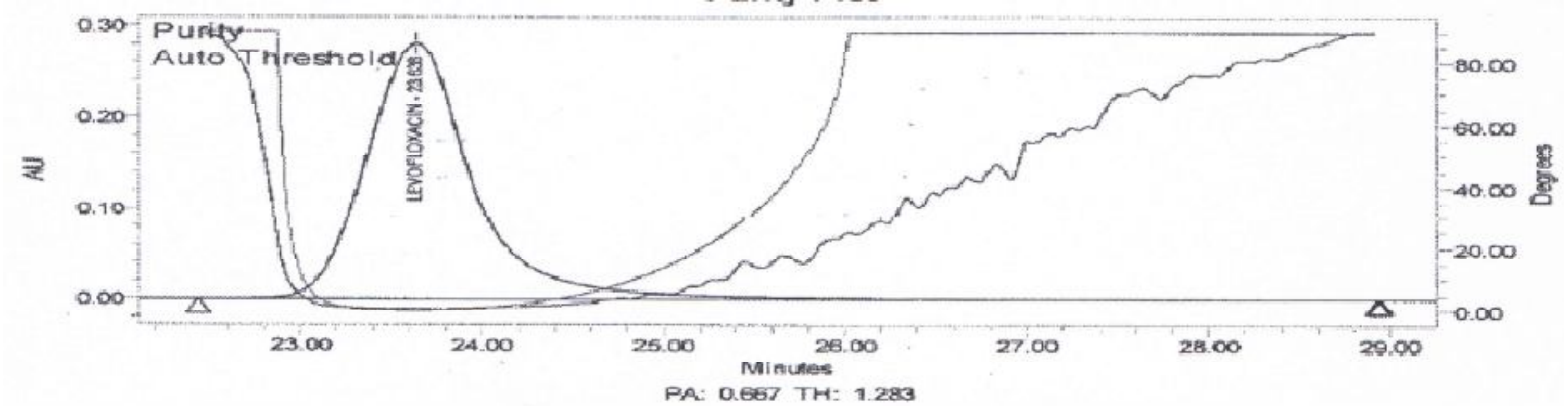

Figure-7: Acid degradation sample peak purity plot

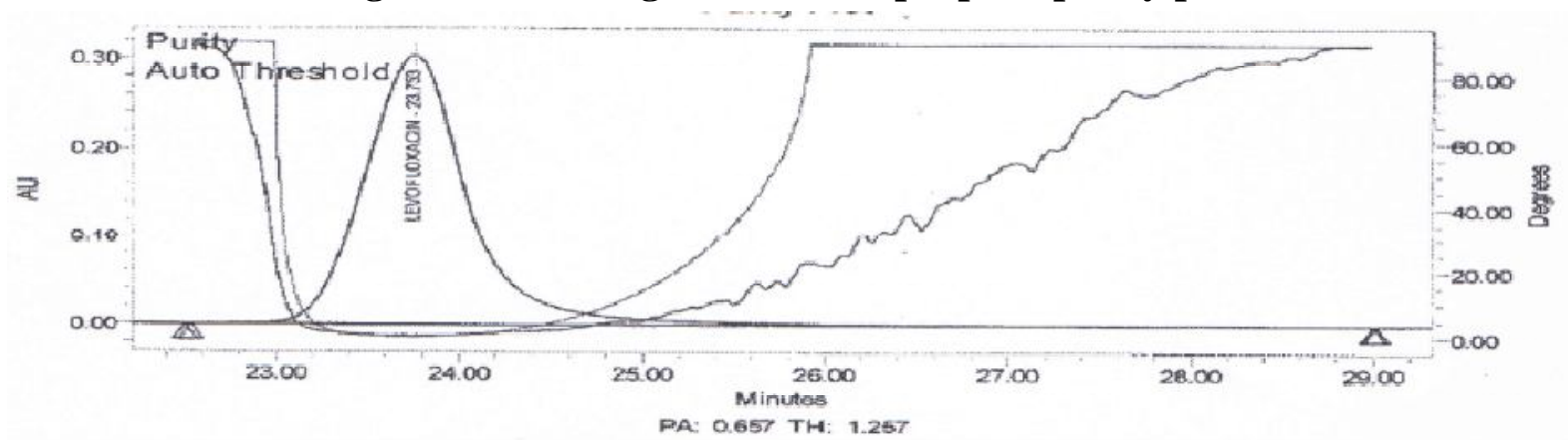

Figure-8: Base degradation sample peak purity plot 


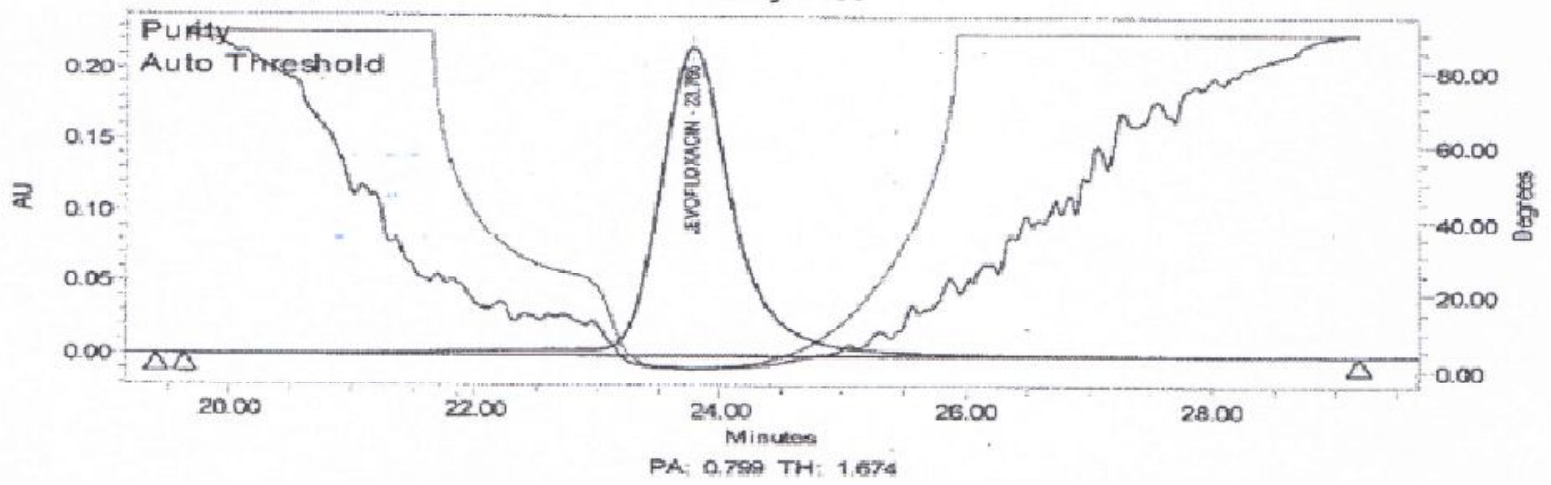

Figure-9: Peroxide degradation sample peak purity plot

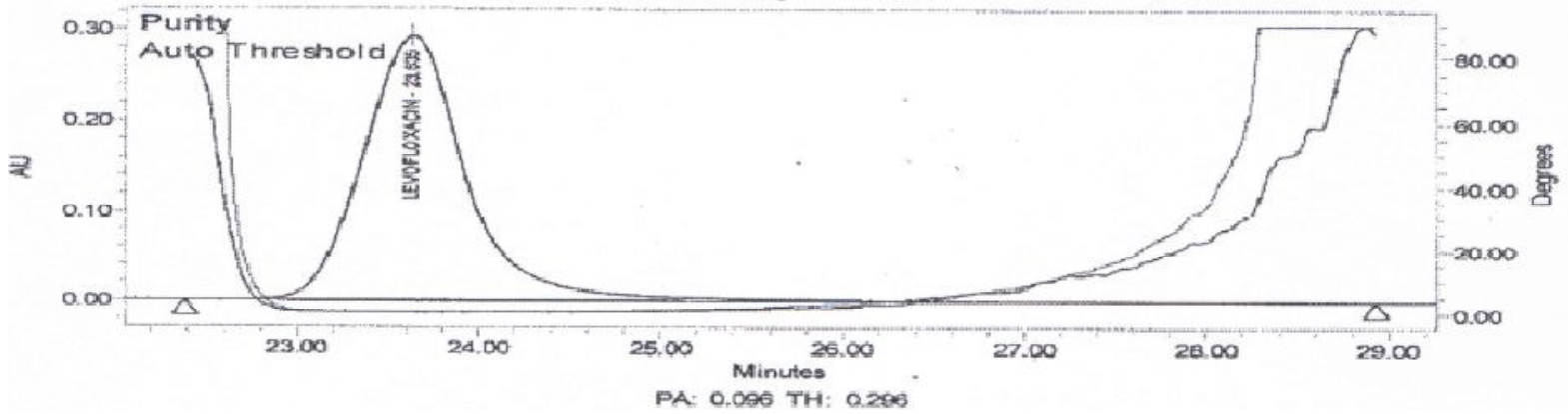

Figure-10: Thermal degradation sample peak purity plot

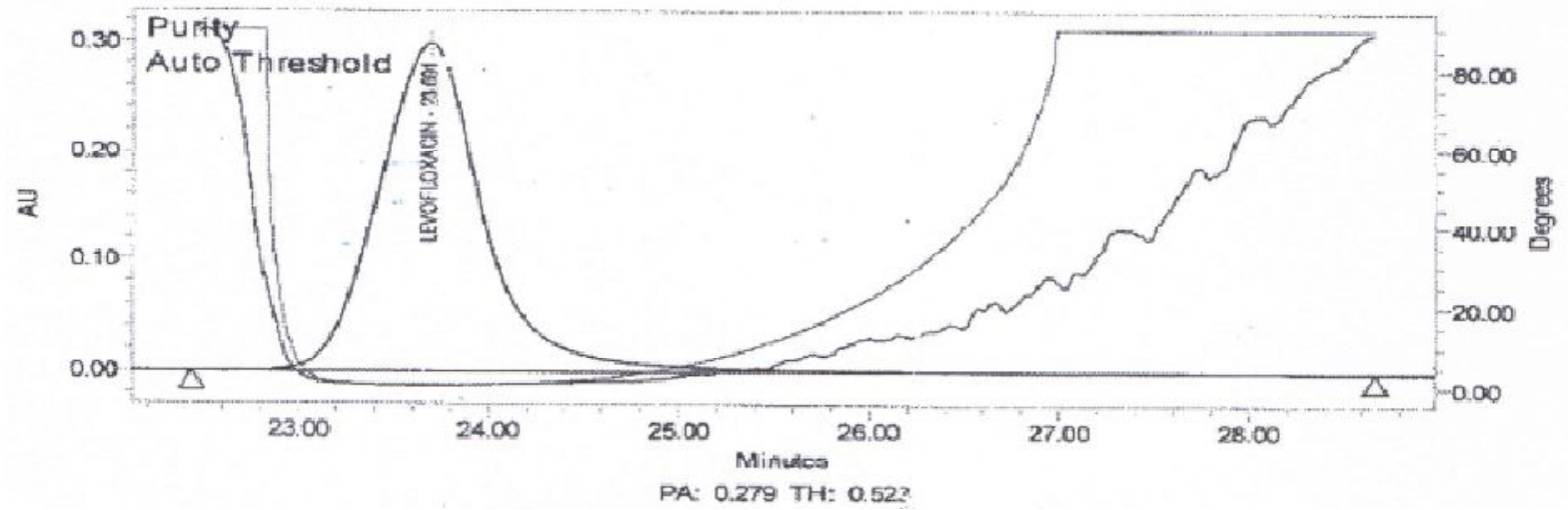

Figure-11: Water degradation sample peak purity plot

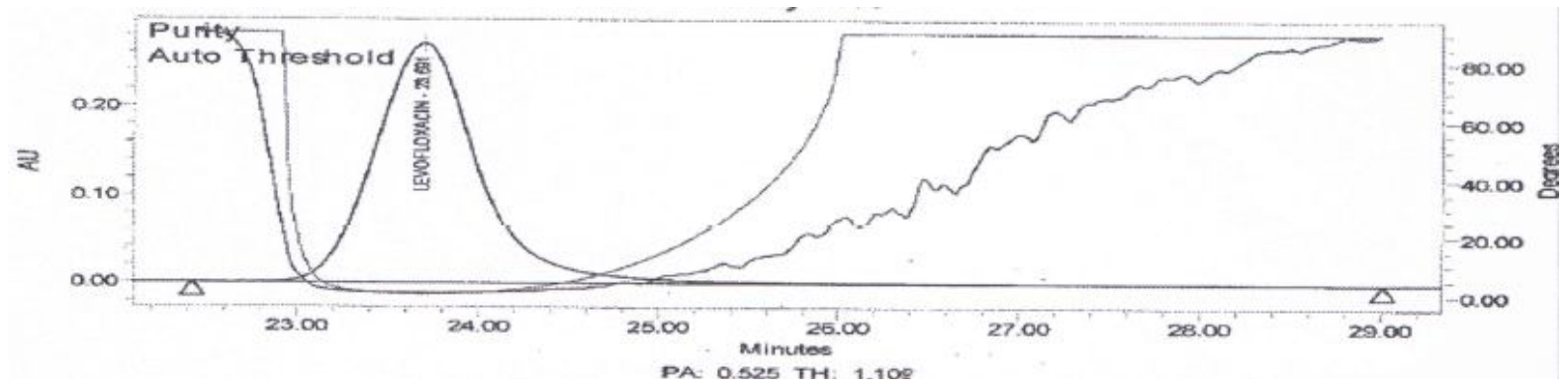

Figure-12: Humidity degradation sample peak purity plot 


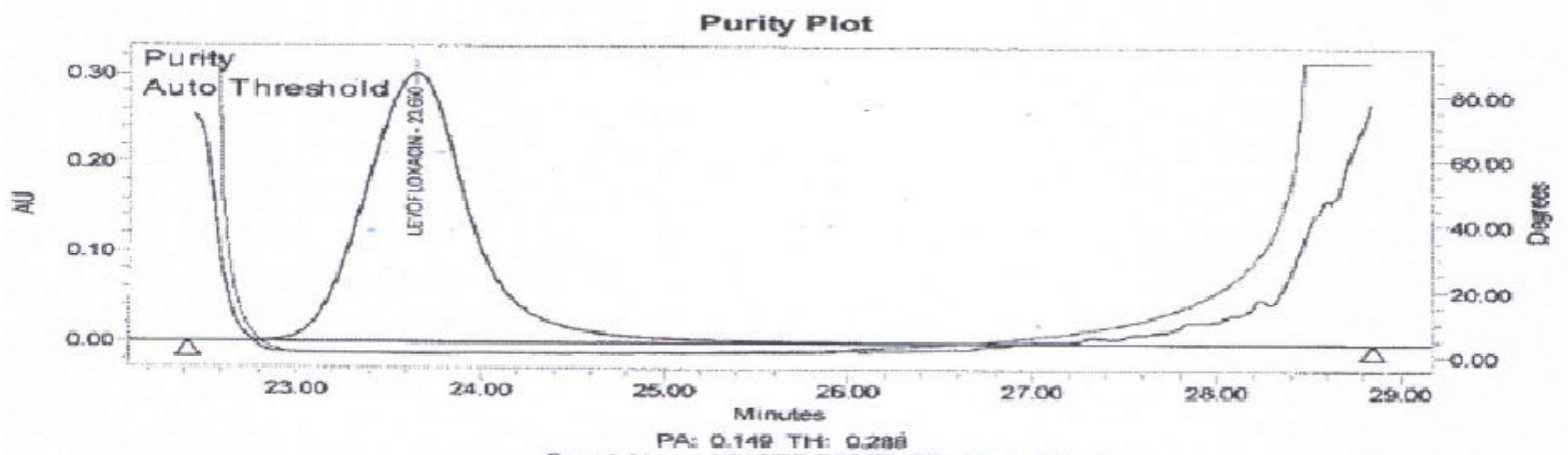

Figure-13: UV light degradation sample peak purity plot

\section{Limit of detection (LOD) and Limit of quantification (LOQ):}

LOD and LOQ were established with signal to noise (S/N ratio) method. S/N ratio values for levofloxacin and its impurities were found from 2.0 to $3.4 \mathrm{LOD}$ concentration and 9.0 to $11.4 \mathrm{LOQ}$ concentration levels. LOQ concentration precision was performed and confirmed the \%RSD. LOD and LOQ concentration chromatograms were represented in figure-14 and 15. LOD and LOQ concentration results were tabulated in table-6.

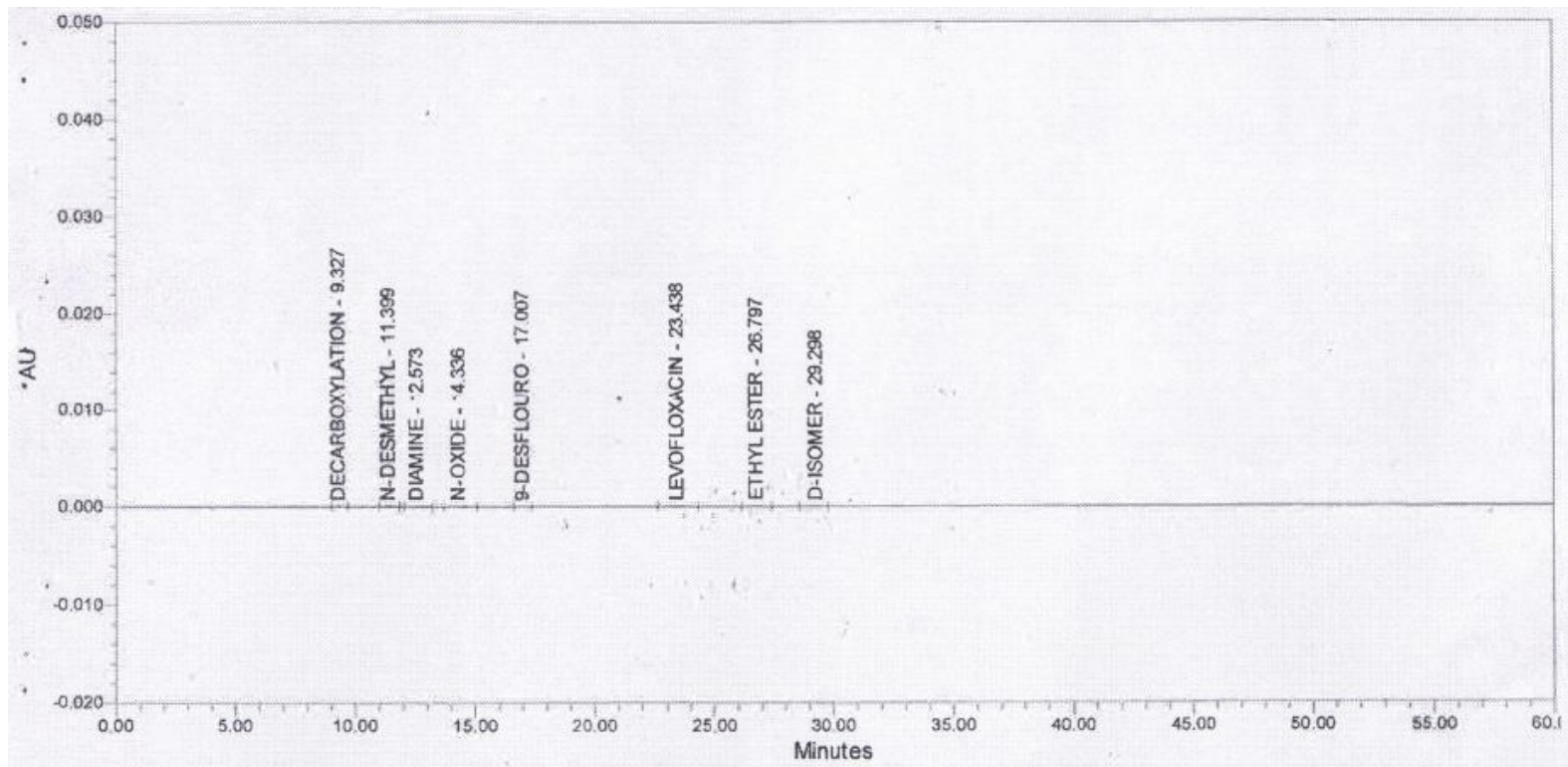

Figure-14: LOD solution chromatogram 


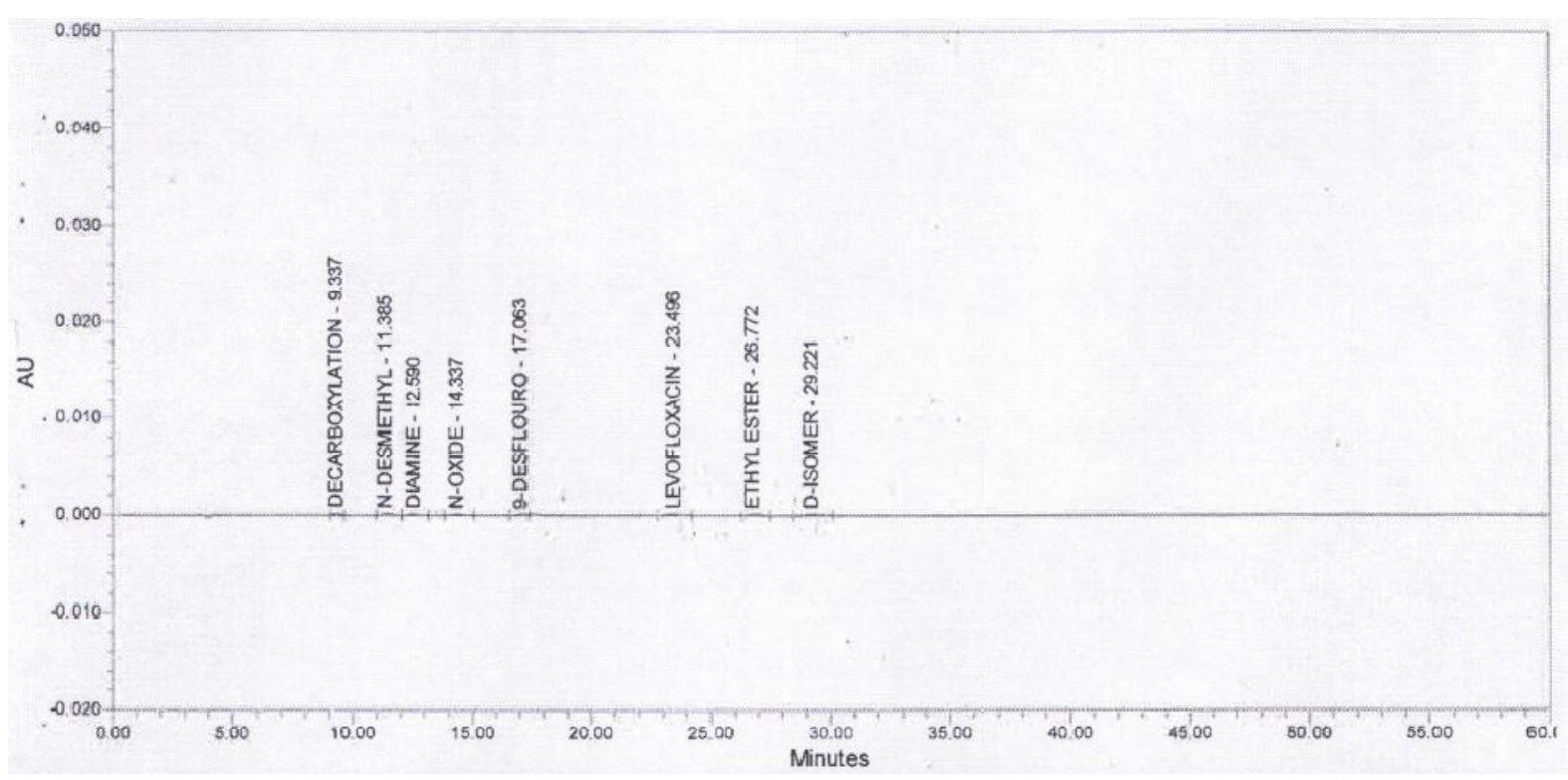

Figure-15: LOQ solution chromatogram

Table-6: LOD and LOQ results

\begin{tabular}{|c|c|c|c|c|c|c|}
\hline \multirow{2}{*}{$\begin{array}{c}\text { Compound } \\
\text { name }\end{array}$} & \multicolumn{3}{|c|}{ LOQ } & \multicolumn{3}{c|}{ LOD } \\
\cline { 2 - 7 } & $\mathbf{p p m}$ & \% level & S/N ratio & ppm & \% level & S/N ratio \\
\hline Levofloxacin & 0.08 & 0.04 & 10.7 & 0.040 & 0.02 & 3.0 \\
\hline $\begin{array}{c}\text { Decarboxylation } \\
\text { imp }\end{array}$ & 0.04 & 0.02 & 10.0 & 0.020 & 0.01 & 29 \\
\hline N-desmethyl imp & 0.05 & 0.025 & 9.5 & 0.025 & 0.01 & 2.8 \\
\hline Diamine imp & 0.05 & 0.025 & 10.6 & 0.025 & 0.01 & 2.5 \\
\hline N-oxide imp & 0.05 & 0.025 & 9.1 & 0.025 & 0.01 & 2.1 \\
\hline 9-desfluro imp & 0.08 & 0.04 & 9.7 & 0.040 & 0.02 & 2.0 \\
\hline Ethyl ester imp & 0.09 & 0.045 & 10.5 & 0.045 & 0.02 & 2.3 \\
\hline D-isomer imp & 0.06 & 0.03 & 11.0 & 0.030 & 0.02 & 2.0 \\
\hline
\end{tabular}




\section{Linearity:}

Linearity was conducted from LOQ concentration to $150 \%$ of the specification limit. Linearity concentration levels are LOQ, 30\%, 50\%, 80\%, 100\%, 130\% and 150\%. Linearity results were calculated for correlation coefficient (area Vs conc.), slope, intercept, bias for $100 \%$ response. Linearity results were tabulated in table-7.

Table-7: Linearity Results

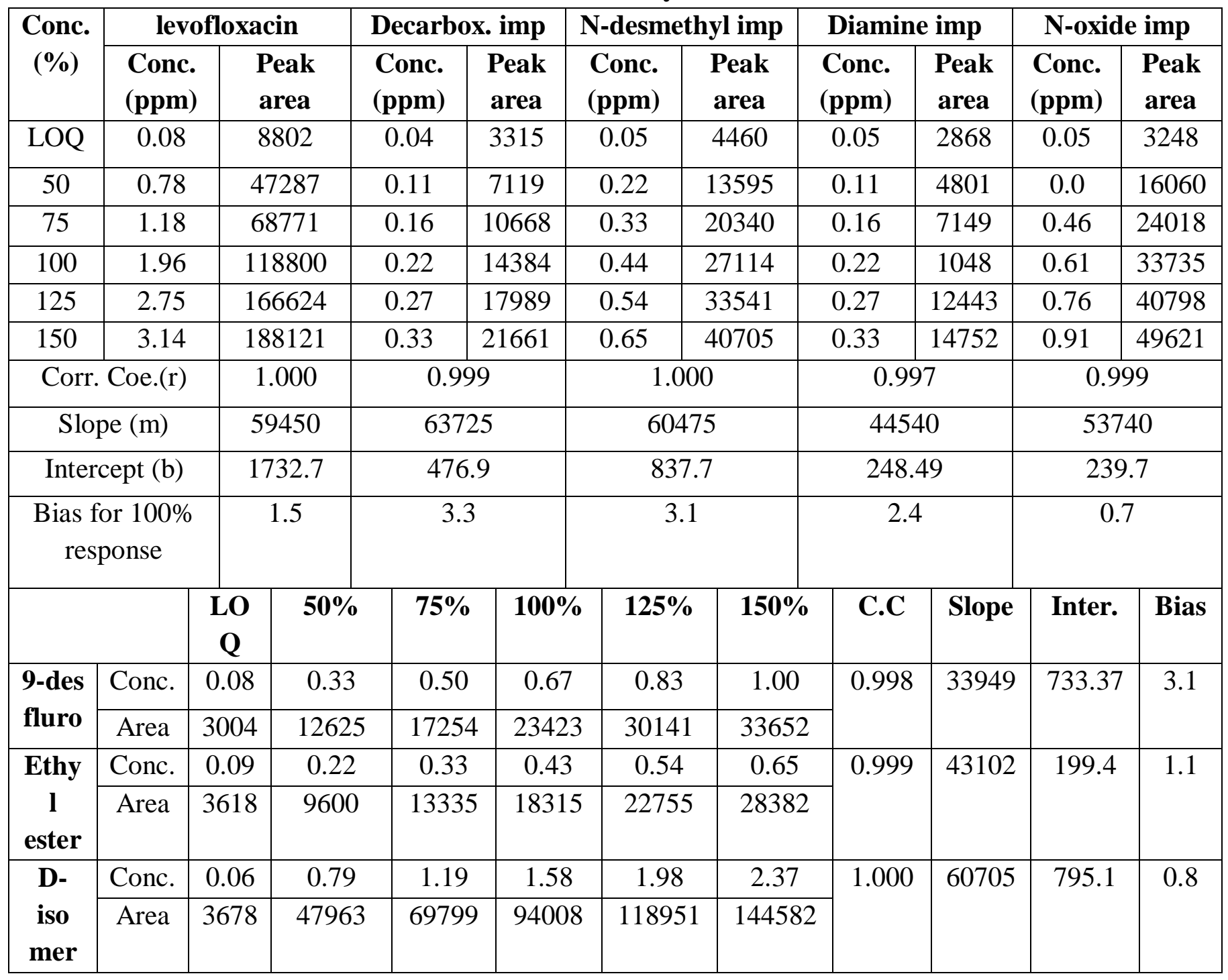

\section{Accuracy:}

Accuracy of the method was validated with three different concentration levels 50\%, 100\% and $150 \%$. $100 \%$ level was performed with six replicate preparations and other $50 \%$ and $150 \%$ levels were three replicates. Recovery was calculated from added concentration and recovered concentrations. Accuracy results were tabulated in table- 8 
Table-8: Accuracy Results

\begin{tabular}{|c|c|c|c|c|c|c|c|c|c|}
\hline \multirow{3}{*}{$\begin{array}{c}\text { Accuracy } \\
\text { level }\end{array}$} & \multicolumn{3}{|c|}{ Decarboxylation imp. } & \multicolumn{3}{|c|}{ N-desmethyl imp } & \multicolumn{3}{|c|}{ Diamine imp } \\
\hline & \multicolumn{2}{|c|}{ Conc. $\mu \mathrm{g} / \mathrm{ml}$} & \multirow{2}{*}{$\begin{array}{c}\% \\
\text { Recovery }\end{array}$} & \multicolumn{2}{|c|}{ Conc. $\mu \mathrm{g} / \mathrm{ml}$} & \multirow{2}{*}{$\begin{array}{c}\% \\
\text { Recovery }\end{array}$} & \multicolumn{2}{|c|}{ Conc. $\mu \mathrm{g} / \mathrm{ml}$} & \multirow{2}{*}{$\begin{array}{c}\% \\
\text { Recovery }\end{array}$} \\
\hline & Added & Found & & Added & Found & & Added & Found & \\
\hline \multirow{3}{*}{$50 \%$} & \multirow{3}{*}{0.110} & 0.102 & 93.0 & \multirow{3}{*}{0.218} & 0.216 & 99.3 & \multirow{3}{*}{0.109} & 0.112 & 102.5 \\
\hline & & 0.104 & 94.8 & & 0.214 & 98.3 & & 0.118 & 108.0 \\
\hline & & 0.104 & 94.8 & & 0.218 & 100.2 & & 0.124 & 113.4 \\
\hline \multirow{6}{*}{$100 \%$} & \multirow{6}{*}{0.219} & 0.198 & 90.3 & \multirow{6}{*}{0.45} & 0.424 & 97.4 & \multirow{6}{*}{0.219} & 0.230 & 105.3 \\
\hline & & 0.212 & 96.7 & & 0.444 & 102.0 & & 0.238 & 108.9 \\
\hline & & 0.202 & 92.1 & & 0.432 & 99.3 & & 0.220 & 100.7 \\
\hline & & 0.208 & 94.8 & & 0.440 & 101.1 & & 0.232 & 106.2 \\
\hline & & 0.202 & 92.1 & & 0.418 & 96.1 & & 0.216 & 98.9 \\
\hline & & 0.204 & 93.0 & & 0.432 & 99. & & 0.224 & 102.5 \\
\hline \multirow{3}{*}{$150 \%$} & \multirow{3}{*}{0.329} & 0.34 & 104.3 & \multirow{3}{*}{0.653} & 0.662 & 101.4 & \multirow{3}{*}{0.328} & 0.334 & 101.9 \\
\hline & & 0.339 & 103.0 & & 0.656 & 100.5 & & 0.334 & 101.9 \\
\hline & & 0.348 & 105.7 & & 0.668 & 102.3 & & 0.344 & 104.9 \\
\hline & \multicolumn{3}{|c|}{ N-oxide imp } & \multicolumn{3}{|c|}{ 9-desfluro imp } & \multicolumn{3}{|c|}{ Ethyl ester imp } \\
\hline \multirow{3}{*}{$50 \%$} & \multirow{3}{*}{0.304} & 0.334 & 109.7 & & 0.352 & 105.8 & & 0.176 & 90.7 \\
\hline & & 0.338 & 111.0 & 0.333 & 0.348 & 104.6 & 0.195 & 0.174 & 89.7 \\
\hline & & 0.340 & 111.7 & & 0.352 & 105.8 & & 0.178 & 91.8 \\
\hline & & 0.626 & 102.8 & & 0.656 & 98.6 & & 0.374 & 96.4 \\
\hline & & 0.662 & 108.7 & & 0.692 & 104.0 & & 0.402 & 103.6 \\
\hline & & 0.640 & 105.1 & & 0.670 & 100.7 & & 0.376 & 96.9 \\
\hline $100 \%$ & 0.009 & 0.650 & 106.7 & 0.000 & 0.690 & 103.7 & 0.390 & 0.390 & 100.5 \\
\hline & & 0.634 & 104.1 & & 0.664 & 99.8 & & 0.380 & 97.9 \\
\hline & & 0.640 & 105.1 & & 0.674 & 101.3 & & 0.378 & 97.4 \\
\hline & & 0.958 & $\begin{array}{l}104.9 \\
\end{array}$ & & 1.014 & 101.6 & & 0.576 & 99.0 \\
\hline $150 \%$ & 0.913 & 0.954 & 104.5 & 0.998 & 1.002 & 100.4 & 0.585 & 0.574 & 98.6 \\
\hline & & 0.976 & 106.9 & & 1.016 & $\begin{array}{l}101.8 \\
\end{array}$ & & 0.586 & 100.7 \\
\hline & & & & D-ison & er imp & & & & \\
\hline & & 0.804 & 101.7 & & & & & 1.566 & 99.0 \\
\hline $50 \%$ & 0.791 & 0.786 & 99.4 & & & & & 1.688 & 106.8 \\
\hline & & 0.814 & 103.0 & & & $80 \%$ & 1501 & 1.614 & 102.1 \\
\hline & & 2.468 & 104.1 & & & $00 \%$ & 1.581 & 1.658 & 104.9 \\
\hline $150 \%$ & 2.372 & 2.434 & 102.6 & & & & & 1.574 & 99.6 \\
\hline & & 2.498 & 105.3 & & & & & 1.618 & 102.3 \\
\hline
\end{tabular}




\section{Ruggedness:}

Ruggedness of the chromatographic conditions was evaluated with intermediate precision such as different analyst, different HPLC system and column. Intermediate precision results found satisfactory and results were listed in precision. Solution stability (mobile phase, standard and test solutions) were evaluated for day-0, day-1 and day-2. Ruggedness results were tabulated in table-9 and 10 .

Table-9: Ruggedness results (solution stability)

\begin{tabular}{|c|c|c|c|c|c|c|c|}
\hline \multirow{2}{*}{\multicolumn{2}{|c|}{$\begin{array}{c}\text { Stability condition } \\
\text { Time in days }\end{array}$}} & \multicolumn{3}{|c|}{ Bench top } & \multicolumn{3}{|c|}{ Refrigerator } \\
\hline & & Day-0 & Day-1 & Day-2 & Day-0 & Day-1 & Day-2 \\
\hline \multicolumn{2}{|c|}{ Std. similarity factor } & NA & 0.97 & 0.98 & NA & 0.98 & 0.97 \\
\hline \multirow[t]{2}{*}{ Total impurities } & Test-1 & 2.053 & 1.978 & 1.992 & 2.053 & 1.996 & 1.951 \\
\hline & Test-2 & 2.165 & 2.150 & 1.963 & 2.165 & 2.113 & 2.073 \\
\hline \multirow{2}{*}{$\begin{array}{l}\text { Decarboxylation } \\
\text { imp }\end{array}$} & Test-1 & 0.099 & 0.099 & 0.099 & 0.099 & 0.099 & 0.099 \\
\hline & Test-2 & 0.106 & 0.104 & 0.106 & 0.106 & 0.106 & 0.105 \\
\hline \multirow{2}{*}{$\begin{array}{l}\text { N-desmethyl } \\
\text { imp }\end{array}$} & Test-1 & 0.214 & 0.207 & 0.204 & 0.214 & 0.207 & 0.201 \\
\hline & Test-2 & 0.221 & 0.220 & 0.216 & 0.221 & 0.222 & 0.219 \\
\hline \multirow[t]{2}{*}{ Diamine imp } & Test-1 & 0.115 & 0.108 & 0.112 & 0.115 & 0.119 & 0.114 \\
\hline & Test-2 & 0.119 & 0.114 & 0.112 & 0.119 & 0.116 & 0.112 \\
\hline \multirow[t]{2}{*}{ N-oxide imp } & Test-1 & 0.313 & 0.308 & 0.299 & 0.313 & 0.305 & 0.303 \\
\hline & Test-2 & 0.331 & 0.324 & 0.316 & 0.331 & 0.325 & 0.314 \\
\hline \multirow[t]{2}{*}{ 9-desfluro imp } & Test-1 & 0.328 & 0.309 & 0.303 & 0.328 & 0.314 & 0.299 \\
\hline & Test-2 & 0.346 & 0.335 & 0.319 & 0.346 & 0.334 & 0.314 \\
\hline \multirow[t]{2}{*}{ Ethyl ester imp } & Test-1 & 0.187 & 0.171 & 0.159 & 0.187 & 0.172 & 0.161 \\
\hline & Test-2 & 0.201 & 0.179 & 0.169 & 0.201 & 0.178 & 0.168 \\
\hline \multirow[t]{2}{*}{ D-isomer imp } & Test-1 & 0.797 & 0.776 & 0.816 & 0.797 & 0.780 & 0.775 \\
\hline & Test-2 & 0.841 & 0.874 & 0816 & 0.841 & 0.833 & 0.842 \\
\hline
\end{tabular}


Table-10: Ruggedness results (mobile phase stability)

\begin{tabular}{|c|c|c|c|c|c|c|c|c|}
\hline $\begin{array}{c}\text { M.P. Bench } \\
\begin{array}{c}\text { top } \\
\text { stability }\end{array}\end{array}$ & \multicolumn{2}{|c|}{ Total impurities } & \multicolumn{2}{c|}{$\begin{array}{c}\text { Decarboxylation } \\
\text { imp }\end{array}$} & \multicolumn{2}{c|}{ N-desmethyl imp } & \multicolumn{2}{c|}{ Diamine imp } \\
\cline { 2 - 9 } & Test-1 & Test-2 & Test-1 & Test-2 & Test-1 & Test-2 & Test-1 & Test-2 \\
\hline Day-0 & 2.053 & 2.165 & 0.099 & 0.106 & 0.214 & 0.221 & 0.115 & 0.119 \\
\hline Day-1 & 2.057 & 2.036 & 0.102 & 0.216 & 0.216 & 0.215 & 0.116 & 0.110 \\
\hline Day-2 & 2.041 & 2.029 & 0.104 & 0.213 & 0.213 & 0.212 & 0.110 & 0.115 \\
\hline & \multicolumn{2}{|c|}{ N-oxide imp } & \multicolumn{2}{|c|}{ 9-desfluro imp } & \multicolumn{2}{c|}{ Ethyl ester imp } & D-isomer imp \\
\hline Day-0 & 0.313 & 0.313 & 0.328 & 0.346 & 0.187 & 0.201 & 0.797 & 0.841 \\
\hline Day-1 & 0.317 & 0.314 & 0.33 & 0.325 & 0.172 & 0.173 & 0.803 & 0.799 \\
\hline Day-2 & 0.313 & 0.312 & 0.319 & 0.313 & 0.168 & 0.167 & 0.813 & 0.804 \\
\hline
\end{tabular}

\section{Robustness:}

Robustness was performed to confirm the changes in the test procedure such as mobile phase solvent ratio, $\mathrm{pH}$, flow rate and column oven temperature. Sample preparation filter validation was performed with PVDF and NYLON filters. Robustness filter validation results were satisfactory and tabulated in table-11. Method changes results were represented in table- 12 .

Table-11: Robustness results (Filter validation)

\begin{tabular}{|c|c|c|c|c|c|c|c|c|}
\hline \multirow{2}{*}{$\begin{array}{c}\text { Filter } \\
\text { solution }\end{array}$} & \multicolumn{3}{|c|}{ Total impurities } & \multicolumn{2}{c|}{$\begin{array}{c}\text { Decarboxylation } \\
\text { imp }\end{array}$} & \multicolumn{2}{c|}{ N-desmethyl imp } & \multicolumn{2}{c|}{ Diamine imp } \\
\cline { 2 - 9 } & Test-1 & Test-2 & Test-1 & Test-2 & Test-1 & Test-2 & Test-1 & Test-2 \\
\hline Centrifuged & 2.072 & 2.051 & 0.109 & 0.111 & 0.225 & 0.220 & 0.122 & 0.119 \\
\hline PVDF & 2.067 & 2.044 & 0.115 & 0.110 & 0.226 & 0.224 & 0.115 & 0.111 \\
\hline NYLON & 2.083 & 2.017 & 0.114 & 0.112 & 0.235 & 0.218 & 0.122 & 0.112 \\
\hline & N-oxide imp & \multicolumn{2}{|c|}{ 9-desfluro imp } & \multicolumn{2}{c|}{ Ethyl ester imp } & \multicolumn{2}{c|}{ D-isomer imp } \\
\hline Centrifuged & 0.322 & 0.313 & 0.292 & 0.290 & 0.177 & 0.173 & 0.282 & 0.824 \\
\hline PVDF & 0.320 & 0.323 & 0.285 & 0.282 & 0.173 & 0.178 & 0.834 & 0.816 \\
\hline NYLON & 0.322 & 0.310 & 0.290 & 0.281 & 0.178 & 0.171 & 0.822 & 0.813 \\
\hline
\end{tabular}


Table-12: Robustness results (Method changes)

\begin{tabular}{|c|c|c|c|c|c|c|c|c|c|}
\hline \multirow{2}{*}{$\begin{array}{c}\text { Levofloxacin system } \\
\text { suitability }\end{array}$} & \multicolumn{3}{|c|}{$\begin{array}{c}\text { Flow rate } \\
\text { (ml/min) }\end{array}$} & \multicolumn{3}{c|}{$\begin{array}{c}\text { Column oven temperature } \\
\left({ }^{\circ} \mathbf{C}\right)\end{array}$} & \multicolumn{3}{c|}{$\begin{array}{c}\text { M.P organic solvent } \\
\text { ratio }\end{array}$} \\
\cline { 2 - 10 } & $\mathbf{0 . 6}$ & $\mathbf{0 . 7}$ & $\mathbf{0 . 8}$ & $\mathbf{3 7}$ & $\mathbf{4 2}$ & $\mathbf{4 7}$ & $\mathbf{9 0 \%}$ & $\mathbf{1 0 0 \%}$ & $\mathbf{1 1 0 \%}$ \\
\hline $\begin{array}{c}\text { Tailing factor (NMT } \\
\text { 1.8) }\end{array}$ & 1.2 & 1.1 & 1.2 & 1.2 & 1.1 & 1.2 & 1.2 & 1.1 & 1.2 \\
\hline \%RSD (NMT 10\%) & 0.6 & 0.2 & 0.8 & 0.6 & 0.2 & 1.4 & 1.7 & 0.2 & 07 \\
\hline
\end{tabular}

\section{Conclusion:}

Levofloxacin and its impurities were separated and quantified with simple and rugged HPLC method. Method equivalency was performed against the USP pharmacopeia method. Equivalency results were satisfactory and method validation was performed to confirm the method extendedness. Validation results were satisfactory precision \%RSD, degradation results, correlation coefficient, \% recovery and system suitability. Eventually, results confirmed that this method can be used to check the regular manufacturing activity.

\section{References:}

1. G. Coria, T. Pérez, I. Sirés, E. Brillas, J.L. Nava, Chemosphere. 2018, 198, 174-81.

2. C.N. Murphy, R.C. Fowler, A.J. Williams, P.C. Iwen, P.D. Fey, United States 2014-2015. Foodborne pathogens and disease. 2018, 15(4), 235-8.

3. D. Deshpande, J.G. Pasipanodya, S.G. Mpagama, P. Bendet, S. Srivastava, T. Koeuth, P.S. Lee, S.M. Bhavnani, P.G. Ambrose, G. Thwaites, S.K. Heysell. Clinical Infectious Diseases. 2018,67(suppl_3), S293-302.

4. W. Ling, W. Ben, K. Xu, Y. Zhang, M. Yang, Z. Qiang. Chemosphere. 2018, 195, 252-9.

5. C.A. Peloquin, P.P. Phillips, C.D. Mitnick, K. Eisenach, R.F. Patientia, L. Lecca, E. Gotuzzo, N.R. Gandhi, D. Butler, A.H. Diacon, B. Martel. Antimicrobial agents and chemotherapy. 2018, 62(10), e00770-18.

6. A.W. Shih, A.S. Lam, T.E. Warkentin. Journal of pharmacy practice. 2018, 31(2), 234-7.

7. J.W. Al Ramahi, M. Ramadan, W. Jaber, L. Abushanab, M. Mughrabi, N. Alshamayleh, A. Mulhem, D. Momani, M. Obaidat, G. Haddad, B. Khalil. The Journal of Infection in Developing Countries. 2018, 12(10), 878-86.

8. J.A. Goswami, N.J. Shah. International journal of pharmaceutical sciences and research. 2018, 9(12), 5197-203.

9. L. Sivasubramanian, D. Balanagamani, R. Mamatha. Journal of Pharmacy Research, Vol. 2018, 12(5), 679.

10. P.V. Gupta, A.M. Nirwane, M.S. Nagarsenker. AAPS PharmSciTech. 2018, 1-4.

11. J. Zhou, Y. Chen, M. Luo, F. Deng, S. Lin, W. Wu, G. Li, K. Nan. Drug Development and Industrial Pharmacy. 2019, 1-36. 
12. A.S. Eldin, M.M. Abdel-Moety, A.S. El-Tantawy, A. Shalaby, M. El-Maamly. Oriental Journal of Chemistry. 2018, 34(2), 913-21.

13. P.K. Sahu, N.R. Ramisetti, T. Cecchi, S. Swain, C.S. Patro, J. Panda. Journal of pharmaceutical and biomedical analysis. 2018, 147, 590-611.

14. S. Ghimire, K. van Hateren, N. Vrubleuskaya, R. Koster, D. Touw, J.W. Alffenaar. J Appl Bioanal. 2018, 4(1), 31 